
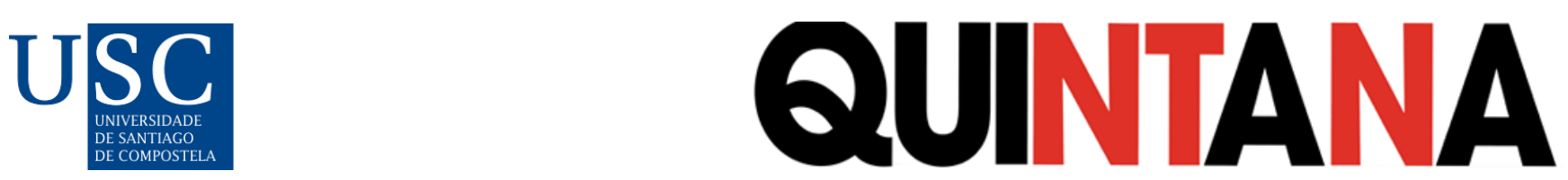

Quintana: revista do Departamento de Historia da Arte, (20), 2021. ISSN-e: 2340-0005

https://doi.org/10.15304/quintana.20.7450

Reseñas

\title{
The city of blue and white: Chinese porcelain and the early modern world. Anne Gerritsen, Cambridge University Press, 2020. 354 págs. ISBN 978-11-0849-995-8
}

Tian Zeng ${ }^{1}(\mathbb{D}$

${ }^{1}$ Universitat de València, España

La globalización de la porcelana china se ha estudiado desde diversas áreas, no obstante, han sido pocos los estudios realizados con una perspectiva tan particular como la de este libro, situándose en un contexto que atraviesa las fronteras culturales, lingüísticas y disciplinarias, que se enfoca en el ámbito local de Jingdezhen, el lugar de producción de la porcelana azul y blanca. La autora, combinando los objetos y los textos, el arte y la sociedad china y del resto del mundo, muestra cómo la ciudad azul y blanca desempeñaba un importante papel en la circulación de bienes, personas e ideas en los albores del mundo moderno, además de analizar la relación y el valor entre la producción local y el consumo global.

El texto se inicia con el mercado de piezas de Jingdezhen, un importante productor mundial de porcelana, donde las historias globales se asocian a las locales para vincular el mercado contemporáneo con el pasado. Al rastrear las trayectorias tecnológicas de la producción de cerámica, las políticas oficiales y las prácticas informales que dirigieron el comercio de la cerámica, como los patrones de consumo doméstico y global, se demuestra la forma en que todos los actores involucrados en la producción de cerámica participaron en estos procesos globales. Asimismo, se ofrece una nueva perspectiva que (re)inserta un punto de vista chino en la discusión de la circulación global de su porcelana, con el fin de descubrir las conexiones intrínsecas y los patrones de interacción que dieron forma al mundo moderno temprano, a la vez que el papel que China desempeñó en él.

Evidentemente, la autora no pretende hacer un análisis exhaustivo, sino profundizar en cómo y por qué Jingdezhen se convirtió en el productor de cerámica más importante del mundo y mantuvo esa posición de privilegio durante siglos. Esta obra está dividida en doce capítulos, siguiendo la secuencia lineal de la historia, en la que cada uno tiene un enfoque determinado. Comienza presentando el reconocimiento de la calidad de la porcelana blanca en dicha región por parte de la realeza, así como de las formas en que la porcelana blanca de Jingdezhen inició su circulación por el extranjero en los siglos XII y XIII, señalando que la clave del temprano desarrollo de Jingdezhen no radicaba sólo en la calidad de los recursos locales o en la demanda de los consumidores de ultramar, sino en la interacción entre ambas esferas por medio de la difusión del conocimiento; centrándose en la aparición y propagación de la ornamentación azul: la introducción del cobalto extraído de las minas del Imperio chino y de Asia Central condujo a la creación del producto más 
destacado y conocido de Jingdezhen, la porcelana azul y blanca, argumentando así que la interacción entre lo global y lo local surge aquí en forma física; conteniendo información sobre Jingdezhen en el siglo XVI, lo que permite conocer a fondo el lugar y su contexto espacial; indagando en la gestión local de los recursos para adentrarse en la organización de la producción y el trabajo en sus talleres; por último, pone el foco en los propios artículos, mostrando que estos también relacionan los factores locales con el consumo global. Ante estas perspectivas, se observa que, a veces, son los condicionantes locales los que mejor explican por qué se producen cambios y transiciones importantes, a veces son los regionales y, en ocasiones, la explicación viene de más lejos.

Gerritsen integra documentos sobre la porcelana de Jingdezhen de distintos lugares y épocas en varios idiomas, con argumentos sólidos que se adhieren a la teoría central de que 'global history can only be written by taking the local seriously'. Se insiste en que tanto la producción como el consumo de la porcelana deben estudiarse desde una perspectiva global, porque sus materiales y diseños transculturales, sus movimientos transnacionales y sus significados múltiples así lo exigen. Pero lo global nunca puede estudiarse a expensas del espesor de la descripción local y del compromiso con las fuentes locales. La historia de la porcelana en Jingdezhen nunca ha sido solo la de una ciudad, sino la de una red de conexiones que vinculan el espacio geográfico, los recursos naturales y las habilidades humanas, pues la clave para entender su desarrollo y cambio es la combinación de factores locales y globales.

Considero de especial relevancia el hecho de que la autora haya seguido con gran atención la aparición y difusión de la ornamentación azul y blanca en Jingdezhen. Gerritsen argumenta que la innovación de Jingdezhen de la decoración en azul cobalto bajo vidriado sobre una superficie de cerámica blanca se basó no solo en la introducción del cobalto, sino también en la adopción en dicha ciudad de la técnica de la pintura bajo vidriado, en particular la aplicación de pigmentos metálicos sobre las superficies no vidriadas de la cerámica para crear dibujos de líneas y decoraciones pintadas con pincel. Ese proceso se inició en los hornos del norte, sobre todo en la amplia región en la que se fabricaba la cerámica de Cizhou de tipología homónima. A lo largo del tiempo, los hornos del sur también empezaron a aplicar decoraciones pintadas con pincel bajo la aplicación del vidriado, a medida que los objetos, las ideas y las personas se desplazaban hacia el sur. En este sentido, Jizhou tuvo un papel clave en la transmisión y circulación de materiales y tecnologías.

Posteriormente, la autora se apoya en cuatro ejemplos: un manuscrito del siglo XIV procedente de Bagdad, un manual de etiqueta de la Corea del siglo XV, un naufragio en Filipinas y un cuadro del Renacimiento italiano, que combinan la singularidad exótica y el significado local para poner de manifiesto, una vez más, que la historia de la porcelana es una historia en la que se entrelazan los significados globales y locales. De este modo, es la combinación de lo global y local lo que ha dado forma a la historia de Jingdezhen, las interacciones multifacéticas e impredecibles a nivel local, regional, escala imperial y mundial que nos permiten comprender realmente la aparición de la porcelana azul y blanca como una característica distintiva de la época. 